PROGRESS IN ORGANIC COATINGS 75 (2012) 480-485

http://dx.doi.org/10.1016/j. porgcoat.2012.06.006

\title{
SECM study of steel corrosion under scratched microencapsulated epoxy resin
}

\author{
A. Pilbáth, T. Szabó, J. Telegdi, L. Nyikos
}

Research Centre for Natural Sciences, Hungarian Academy of Sciences, Institute of Materials and Environmental Chemistry

H-1025 Budapest, Pusztaszeri út 59-67, Hungary

szabo.84.tamas@ttk.mta.hu, telegdi.judit@ttk.mta.hu, nyikos.lajos@.ttk.mta.hu

Corresponding author: pilbath.aranka@ttk.mta.hu

Phone: +36-1-438-1138

\begin{abstract}
Scratch tests were performed on epoxy coated steel samples with and without microcapsulated linseed oil, known to develop a polymerized protective layer after having been released from the capsules at the damaged sites. The scanning electrochemical microscope has been applied to monitor the protection efficiency of this self-healing coating in aqueous acidic solution. In the proximity of the local damage, both the anodic metal dissolution and the cathodic oxygen reduction showed that the coating with microcapsules substantially and spontaneously decreased the rate of corrosion proving the self-repair concept of the coating. Electrochemical impedance measurements underline the protective effect of the coating as well.
\end{abstract}

Keywords: SECM, EIS, self-healing, iron dissolution, microcapsules, epoxy primer 


\section{Introduction}

Polymeric coatings are commonly used to isolate metals from the corrosive environment, but the protection efficiency can decrease substantially if the coating is damaged. Traditionally, the only remedy was to renew or otherwise manually repair the deteriorated coating. Recently, however, the concept of self-healing, self-repairing coatings emerged in the research of functional polymers. The main objective is, preferably without manual intervention, the regeneration of the functionality of damaged, cracked coating [1]. The methods of self-healing process vary: some are autonomous, some require external stimulus like temperature increase. Special polymeric chains that are separated by cracking or scratching can reconnect, building up a physical network by intrinsic (chemical/physical interactions) or extrinsic (healer-loaded tubes, fibres, capsules) repairing effects [1]. Hollow carriers, microcapsules containing polymerizable materials like epoxy resin [2], dicyclopentadiene [3, 4], air-drying oil [5] when damaged, break together with the coating, releasing the fluid material. This liquid fills up discontinuities and soon fixes the polymer by initiator, catalyst, latent hardener [3, 6] or other reagent, e.g. air-oxygen [7]. The most explored self-repairing bulk phases are epoxy [3, 4, 8-10] and polyester matrices [11]. Selfhealing microcapsules and slow release microspheres in paints studied by several authors [12] showed that microcapsules built in paint lose their core material which fills the scratch line and so the corrosion damage is diminished by an autonomous self-healing mechanism [13].

There are a few quantitative methods to investigate the defensive, anti-corrosive effect of these coatings [14]. The scanning electrochemical microscope (SECM) [15] has been introduced to the corrosion field, giving valuable microscopic information from a corroding surface [16-20] allowing the measurement of local differences in electrochemical reactivity [21] or $\mathrm{pH}$ [22-24] of the scanned surface [25]. With the SECM, by adequately selecting the potential applied to the microelectrode tip, scanned over the damaged area, both the release of metal ions at the anodic sites and the consumption of oxygen at cathodic sites can be monitored $[26,27]$ at a localized damage site where these anodic and cathodic processes occur in near proximity. The important advantage of the SECM technique is that it operates on both insulating (coated) and conducting (non-coated) surfaces, thus allowing one to easily distinguish between the coated and scratched surfaces [28]. The SECM allows us to monitor in-situ the corrosion taking place within a coating defect [29]. The deterioration of organic coatings through a defect on metallic surfaces [28, 30-32], the spontaneous deterioration of 
the organic coatings on different metals [32-34] and the defect repair in self-healing, shapememory polymer coating [35], and encapsulated silyl esther [36], coil-coated cladding [37] were all monitored by the SECM technique.

Here we show an example for SECM characterization of steel corrosion under scratched epoxy resin coating, with or without encapsulated linseed oil incorporated in the resin. Linseed oil, a mixture of triglyceride esters of unsaturated fatty acids, upon drying in air, is known to form a strong, continuous film due to its oxidative degradation and crosslinking [38]. It is, therefore, an ideal candidate to study autonomous self-healing.

In this paper we report the results of SECM experiments which follow the spontaneous corrosion process occurring at scratched steel surfaces, without and with the protective microcapsulated healing agent. The spontaneous corrosion protection of encapsulated microcapsules embodied into the epoxy primer has been monitored. The scratched surfaces were visualized by scanning electron microscope and by optical/fluorescence microscope.

\section{Experimental}

\subsection{Materials, sample preparation}

The chemicals used for preparation of microcapsules were as follows:

a) Shell-forming materials: urea (Fluka, p.a.), resorcinol (Reanal, purum), formaldehyde (Sigma-Aldrich, purum, 37\%); ammonium-chloride (Reanal, purum); polyvinyl alcohol (PVA) - surfactant (Reanal, purum); b) film forming material - linseed oil (Aldrich, purum). Microcapsules for self-healing coatings were made by emulsion polymerization. In a $200 \mathrm{ml}$ beaker $1.250 \mathrm{~g}$ urea, $0.125 \mathrm{~g}$ resorcinol, $0.125 \mathrm{~g}$ ammonium chlorides were dissolved in $65 \mathrm{ml}$ of $2 \%$ aqueous solution of PVA and $15 \mathrm{ml}$ linseed oil was emulsified with sonication for 5 $\min$ (at $24 \mathrm{kHz}$, with a S7 size microtip). Then the emulsion was stirred at $600 \mathrm{rpm}$ and 3.210 $\mathrm{g}$ of formaldehyde was added to the emulsion. The temperature of the reaction mixture was raised to $70{ }^{\circ} \mathrm{C}$ at a rate of $1{ }^{\circ} \mathrm{C} / \mathrm{min}$ and kept for 5 hours. After cooling down to room temperature the capsules were separated, washed with diluted ethanol or with aqueous surfactant solution to remove excess oil. The capsules were then dried at room temperature. The used two-component epoxy wax was purchased from Ablonczy Ltd. Hungary. Resin 'A' and hardener ' $\mathrm{B}$ ' components were mixed at a volume ratio of 25 to 1. 
Experiments were performed on steel sheets. The composition of the steel sheets was determined by EDX measurements and the results given in at $\%$ are as follows: Fe $(88.6 \pm$ $0.7), \mathrm{C}(10.8 \pm 0.6)$ and $\mathrm{Al}(0.6 \pm 0.1)$.

Wet grinding on silicon carbide abrasive papers (220-4000 grit) was used as surface preparation prior to coating. The steel sheets were ultrasonically cleaned and rinsed with acetone. Finally the samples were dried in argon flow.

Sample preparation steps were as follows:

1. The microcapsules were mixed into the resin in $4 \mathrm{w} / \mathrm{w} \%$.

2. The steel plates were coated with the above mentioned mixture and with the epoxy without microcapsules. The thickness of the dry coating was about 50-60 $\mu \mathrm{m}$.

3. Scratches of either 20 or $200 \mu \mathrm{m}$ width were produced in the coating on the metal substrate by a scalpel or by a sharp needle. The samples were left to dry after scratching for several hours.

The coated and scratched samples were immersed in aerated aqueous solution of $1 \mathrm{M} \mathrm{NaClO}_{4}$ and $1 \mathrm{mM} \mathrm{HClO}_{4}$ at room temperature, and examined in-situ with the SECM across the scratch. The corrosive media was chosen taking in consideration that the perchlorate ions are not exhibiting a specific interaction with the surface, it is an inert electrolyte. The $\mathrm{pH}$ of the electrolyte solution was 2.83 . The specimen was left unbiased at its open-circuit corrosion potential for all experiments. Experiments were conducted at ambient temperature.

\subsection{Experimental methods}

The structure, diameter and the morphology of the microspheres and the scratched surface were visualized by scanning electron microscope (SEM, Zeiss EVO 40 XVP) as well as by optical/fluorescence microscope (Zeiss Axio Imager A1); sonicator applied in emulsification was a Hielscher ultrasound technology UP200S.

A model of Sensolytics Base SECM (Bochum-Germany) was used. The instrument was operated with a $10 \mu \mathrm{m}$ platinum tip as the probe, an $\mathrm{Ag} / \mathrm{AgCl} / \mathrm{KCl}$ (saturated) reference electrode and a platinum counter electrode. All potential values are referred to the $\mathrm{Ag} / \mathrm{AgCl} / \mathrm{KCl}$ (saturated) reference electrode. The diffusion regime for $\mathrm{Fe}$ (II) oxidation was $0.5 \mathrm{~V}$ vs $(\mathrm{Ag} / \mathrm{AgCl}, 3 \mathrm{M} \mathrm{KCl})$ and for the oxygen reduction $-0.7 \mathrm{~V}$ vs $(\mathrm{Ag} / \mathrm{AgCl}, 3 \mathrm{M} \mathrm{KCl})$. The measurements of line scans were generated with the tip at $\sim 10 \mu \mathrm{m}$ from the specimen surface in all the cases. The scan rate was $10 \mu \mathrm{m} / \mathrm{s}$. 
Electrochemical impedance spectroscopy (EIS) measurements were carried out at open-circuit potential using a Zahner Im5d Impedance Spectrum Analyzer. The impedance spectra were recorded in the frequency range between $1 \mathrm{kHz}$ and $25 \mathrm{mHz}$, using a sinusoidal perturbation of $10 \mathrm{mV}$ p-p amplitude. The frequency sweep was started after $15 \mathrm{~min}$ of immersion in the electrolyte and was repeated for $24 \mathrm{~h}$ in every hour. The evaluation of the impedance spectra was made using the EQUIVCRT software written by Boukamp [39] by assuming a parallel combination of a charge transfer resistance and a dispersive double layer impedance (a constant phase element) with a simple series resistance. $R_{1}\left(R_{2} Q\right)$ was found to adequately represent all the data. A standard three -electrode cell was used for the electrochemical measurements. The counter electrode was platinum. The electrode potential was measured against a saturated calomel electrode. The coated electrode whole surface area during the EIS measurement was $3.8 \mathrm{~cm}^{2}$. In the middle of the coated electrode two crossed scratch lines each $1.5 \mathrm{~cm}$ length were made. The results are given in relative values without surface area correction.

\section{Results and discussion}

Fig. 1 presents the structure, size and the morphology of the microspheres visualized by scanning electron microscope. The diameter of the microcapsules was between 3 and 10 microns with a narrow size-distribution peaked at about 6 microns. The fluorescence microscopy pictures of the scratched samples (cf. Fig. 2) show the wide and narrow scratch morphology. The green dots in the resin matrix are the microcapsules.

Prior to each SECM scanning experiment, the tip-sample distance was established by approach curves performed above the insulating part of the coating at $-0.70 \mathrm{~V}$, showing negative-feedback behaviour.

The status of a scratched sample was studied by monitoring the oxidation of dissolved $\mathrm{Fe}^{2+}$ (tip potential: $0.5 \mathrm{~V} v s \mathrm{Ag} / \mathrm{AgCl} /$ saturated $\mathrm{KCl}$ reference electrode) and reduction of oxygen (tip potential: $-0.7 \mathrm{~V}, c f$. Fig. 3-4) in test solutions. Corrosion activity is observed from 10 minutes after immersion in the electrolyte solution. The process of oxidation of $\mathrm{Fe}^{2+}$ is not the best choice after long time exposure into the electrolyte solution because the current decreases quite rapidly. This can be due to the precipitation of corrosion products, which block the active zones and hinder the electrochemical activity of $\mathrm{Fe}^{2+}$ ions. Nevertheless, the dissolution 
of $\mathrm{Fe}^{2+}$ ions can be followed for at least two hours for both the wide and the narrow scratches (Figs. 3 and 4).

The other possibility to follow the corrosion process is to set the tip potential to that of oxygen reduction. By doing so, one initiates a competition for oxygen: oxygen is both consumed by the corrosion process and by the microelectrode. As shown in Fig. 5, oxygen concentration reaching the tip is very low above the scratch indicating a vigorous corrosion process. It can also be seen that as time passes, oxygen concentration decreases further and further away from the damaged site as oxygen is depleted more and more.

The current of oxygen reduction (cf. Fig.5) measured in the middle of the scratch shows a decreasing tendency, not apparent at the scale of Fig.5A, indicating accelerating corrosion even after 2 hours.

Comparing the currents across the scratch on a sample when the microcapsules were incorporated in the coating, with the reference sample (no microcapsules) shows the protection effect of the linseed oil, released from the broken capsules, is able to produce. By monitoring $\mathrm{Fe}^{2+}$ oxidation, the protective effect of the self-healing coating is obvious (Fig. 6). Since, as discussed above, this oxidation current is not a reliable measure of the rate of corrosion at longer times due to insoluble precipitation formation, the oxygen reduction currents are to be monitored.

The corrosion rate, as indicated by the local oxygen consumption, is considerably lower in the microcapsule-protected sample (Fig. 7). By measuring maps, of which an example is shown in Fig. 8, it was proven that the protection effect is fairly uniform along the scratch, i.e. there are no unprotected areas left, thereby validating the capsule density and linseed oil quantities used in the coatings. This finding demonstrates that practical amounts of corrosion protection agents which can be easily incorporated in the capsules are indeed sufficient to offer reliable and uniform protection along the damaged sites.

As a further test, the corrosion behaviour of epoxy coated steel samples with and without microcapsulated linseed oil was followed by electrochemical impedance measurements. The epoxy coated samples of steel sheet with microcapsulated linseed oil modified the metal behaviour in the corrosive medium.

An example of Nyquist plots ( $c f$. Fig. 9) recorded after $1 \mathrm{~h} 15 \mathrm{~min}$ and $24 \mathrm{~h} 15 \mathrm{~min}$ immersion in the corrosive test medium of an epoxy coated steel sample with and without microcapsulated linseed oil. 
The main purpose was to estimate the polarization resistance values of the treated surfaces in comparison with the untreated one. The change of the polarization resistance values are summarized in Fig. 10. The results show that the linseed oil spread on the surface of the electrode had effect on the behaviour of the steel samples. However, the epoxy coated steel samples with microcapsulated linseed oil shows a decreasing tendency in the polarization resistance values, do not reach even after $24 \mathrm{~h}$ of immersion in the electrolyte solution the polarization values of the reference sample.

The electrochemical impedance spectroscopy measurements prove the effect observed with the SECM technique. While the SECM measurement gives local information from the surface of the electrode, the EIS measurement shows a global result from the whole electrode surface, in this case from the whole region of the scratch.

\section{Conclusion}

The present study demonstrates that the SECM is an eminently suitable technique to visualize and to investigate the processes of self-healing in coated steel samples. The protective effect of the microcapsule incorporated linseed oil along the scratched surface of the steel was followed. The SECM tip measured the oxidation and reduction currents participating in the corrosion process. By comparing the corrosion-produced $\mathrm{Fe}^{2+}$ concentration and the oxygen consumption in scratched samples with and without microcapsulated linseed oil, it was established that the capsulated material shows self-healing properties indeed. Our next plan is to incorporate corrosion inhibitors in the microcapsules, which, together with the linseed oil, may cause an even more pronounced protection against corrosion caused by coating damage. Results obtained by the two independent methods (SECM, EIS) proved the surface modification and the protective effect of the linseed oil.

\section{Acknowledgements}

This work was supported by the Grant OTKA under project number of NK 68997.

The authors would like to express their thanks to P. Németh, L. Szabó and E. Drotár for the SEM-EDX measurements. 


\section{References}

[1]. M.Q. Zang, Polymer Letters 2 (2008) 238-250

[2]. L. Yuan, G. Liang, J.Q. Xie, L. Li, J. Guo, Polymer 47 (2006) 5338-5349

[3]. M.R. Kessler, N.R. Sottos, S.R. White, Composites Part A: Applied Science and Manufacturing 34 (2003) 743-753

[4]. S.R. White, N.R. Sottos, P.H. Geubelle, J.S. Moore, M.R. Kessler, S.R. Sriram, E.N.Brown, S. Viswanathan, Nature 409 (2001) 794-797

[5]. A. Kumar, L.D. Stephenson, J.N. Murray, Prog. Org. Coat. 55 (2006) 244-253

[6]. T. Yin, M.Z. Rong, M.Q. Zhang, G.Ch. Yang, Composites Science and Technology 67 (2007) 201-212

[7]. C. Suryanarayana, K.Ch.Rao, D. Kumar, Prog. Org. Coat. 63 (2008) 72-78

[8]. E.N. Brown, M.R. Kessler, N.R. Sottos, S.R. White, Journal of Microencapsulation 20(6) (2003) 719-730

[9]. C.L. Mangun, A.C. Mader, N.R. Sottos, S.R. White, Polymer 51 (2010) 4063-4068

[10]. T. Nesterova, K. Dam-Johansen, S. Kiil, Prog. Org. Coat. 70 (2011) 342-352

[11]. D. Jung, A. Hegeman, N.R. Sottos, P.H. Geubelle, S.R. White, Compos. Funct. Grad. Mater. 80 (1997) 265-275

[12]. M. Samadzadeh, S. Hatami Boura, M. Peikari, S.M. Kasiriha, A. Ashrafi, Prog. Org. Coat. 68 (2010) 159-164

[13]. T. Szabó, L. Molnár-Nagy, J. Bognár, L. Nyikos, J. Telegdi, Prog. Org. Coat. 72 (2011) $52-57$

[14]. K. Mehta, M.N. Bogere, Prog. Org. Coat. 64 (2009) 419-428

[15]. A.J. Bard, M.V. Mirkin (Eds.), Scanning Electrochemical Microscopy, Marcel Dekker, New York, 2001

[16]. Y. González-Garcia, G.T. Burstein, S. Gonzalez, R. M. Souto, Electrochemistry Communications, 6 (2004) 637-642

[17]. R.M. Souto, Y. Gonzalez-Garcia, S. Gonzalez, G.T. Burstein, Corr. Sci. 46 (2004) 26212628

[18]. R.M. Souto, Y. Gonzalez-Garcia, S. Gonzalez, Corr. Sci. 47 (2005) 3312-3323

[19]. R.M. Souto, Y. Gonzalez-Garcia, A.C. Bastos, A.M. Simões Corr. Sci. 49 (2007) 45684580 
[20]. B.B. Katemann, C.G. Inchauspe, P.A. Castro, A. Schulte, E. J. Calvo, W. Schuhmann, Electrochim. Acta 48 (2003) 1115-1121

[21] A.M. Simões, A.C. Bastos, M.G. Ferreira, Y. Gonzalez-Garcia, S. Gonzalez, R.M. Souto, Corr. Sci. 49 (2007) 726-739

[22]. J. Izquierdo, L. Nagy, A’ Varga, J.J. Santana, G. Nagy, R.M. Souto, Electrochim. Acta $56(2011) 8846-8850$

[23]. S.V. Lamaka, M. Taryba, M. F. Montemor, H.S. Isaacs, M.G.S. Ferreira, Electrochem. Commun. 13 (2011) 20-23

[24]. O.V. Karavai, A.C. Bastos, M.L. Zheludkevich, M.G. Taryba, S.V. Lamaka, M.G.S. Ferreira, Electrochim. Acta 55 (2010) 5401-5406

[25]. R.M. Souto, S. V. Lamaka, S. González: Uses of Scanning Electrochemical Microscopy in Corrosion Research In: A. Méndez-Vilas, J. Díaz, Microscopy: Science, Technology, Applications and Education, Microscopy Book Series No. 4, Formatex Research Center Publisher, Vol.3, pp. 1769-1780, (2010).

[26]. A.C. Bastos, A.M. Simões, S. González, Y. González-García, R.M. Souto, Electrochem. Commun. 6 (2004) 1212-1215

[27]. J.J. Santana, J. Gonzáles-Guzmán, L. Fernández-Mérida, S. Gonzáles, R.M.Souto, Electrochim. Acta 55 (2010) 4488-4494

[28]. A.C. Bastos, A.M. Simões, S. Gonzáles, Y. Gonzáles-García, R.M. Souto, Prog. Org. Coat. 53 (2005) 177-182

[29]. M. Arca, A.J Bard, B.R. Horrocks, Th.C. Richards, D.A. Treichel, Analyst 119 (1994) $719-726$

[30]. J.J. Santana, J. Gonzáles-Guzmán, J. Izquierdo, S. Gonzáles, R.M. Souto, Corr.Sci.52 (2010) 3924-3931

[31]. R.M.Souto, Y. González-García, S. González, Corr.Sci. 50 (2008) 1637-1643

[32]. R.M. Souto, Y. Gonzáles-García, S. Gonzáles, Prog. Org. Coat. 65 (2009) 435-439

[33]. R.M. Souto, Y. González-García, J. Izquierdo, S. González, Corr.Sci. 52 (2010) 748-753

[34]. R.M. Souto, J.J. Santana, L. Fernández-Mérida, S. González, Electrochim. Acta 56 (2011) 9596-9601

[35]. Y. Gonzáles-García, J.M.C. Mol, T. Muselle, I. De Graeve, G. Van Assche, G. Scheltjens, B. Van Mele, H. Terryn, Electrochemistry Communications 13 (2011) 169-173 [36]. Y. González-García, S.J. García, A.E. Hughes, J.M.C. Mol, Electrochem. Commun.13 (2011) 1094-1097 
[37]. R. M. Souto, B. Normand, H. Takenouti, M. Keddam, Electrochim. Acta 55 (2010) 5514557

[38]. M. Lazzari, O. Chiantore, Polymer Degradation and Stability 65 (1999) 303-313

[39] B. A. Boukamp, Solid State Ionics 20 (1986) 31-44 


\section{Figure captions}

Fig. 1. SEM micrograph of urea-formaldehyde microcapsules

Fig. 2. SEM images (A,C) and fluorescence micrographs (B,D) taken of a scratched surface of the microcapsule-containing epoxy resin on the coated steel samples. Scratch width: $\sim 200$ $\mu \mathrm{m}(\mathrm{A}, \mathrm{B})$ and $\sim 20 \mu \mathrm{m}(\mathrm{C}, \mathrm{D})$

Fig. 3. Time dependence of the $\mathrm{Fe}^{2+}$ oxidation current across the wide scratch (no microcapsules). Tip potential: $0.5 \mathrm{~V}$ vs $\mathrm{Ag} / \mathrm{AgCl} / \mathrm{KCl}$ reference electrode

Fig. 4. 3D plot of line scans performed by SECM at different immersion times in the electrolyte solution on an epoxy coated and narrow scratched $(20 \mu \mathrm{m})$ steel sample. The $\mathrm{Fe}^{2+}$ oxidation process is monitored. Tip potential: $0.5 \mathrm{~V} v s \mathrm{Ag} / \mathrm{AgCl} / \mathrm{KCl}$ reference electrode. Immersion time: $30 \min (\bullet), 60 \min (\circ), 90 \min (\boldsymbol{\Delta}), 120 \min (\Delta)$

Fig. 5. The oxygen reduction process is monitored. A: 3D plot of line scans performed by SECM at different immersion time in the electrolyte solution on an epoxy coated and scratched $(20 \mu \mathrm{m})$ steel sample. Tip potential: $-0.7 \mathrm{~V} v s \mathrm{Ag} / \mathrm{AgCl} / \mathrm{KCl}$ reference electrode. Immersion times: $10 \min (\bullet), 20 \min (\square), 30 \min (\bullet), 60 \min (\circ), 90 \min (\Delta), 120 \min (\Delta)$. B: The time dependence of oxygen reduction current measured in the middle of the scratch. Fig. 6. Line scans, following the $\mathrm{Fe}^{2+}$ oxidation at $0.5 \mathrm{~V}$ potential value $v s(\mathrm{Ag} / \mathrm{AgCl}, 3 \mathrm{M}$ $\mathrm{KCl}$ ), performed at $30 \mathrm{~min}$ immersion time in the electrolyte solution on a scratched (scratch width: $20 \mu \mathrm{m}$ ) epoxy coated (opened symbols) and a scratched microcapsules embodied epoxy coated steel sample (filled symbols).

Fig. 7. Plots of line scans, monitoring the oxygen reduction process, performed by SECM at different immersion times (indicated on the Figure) in the electrolyte solution on a scratched (scratch width: $20 \mu \mathrm{m}$ ) epoxy coated (open symbols) and a microcapsules embodied epoxy coated steel sample (filled symbols). Tip potential: $-0.7 \mathrm{~V}$ vs $\mathrm{Ag} / \mathrm{AgCl} / \mathrm{KCl}$ reference electrode.

Fig. 8. Topographic map of oxygen reduction in time after 2 hour immersion in the electrolyte on a coated steel sample (A - no microcapsules, B - microcapsules) with a $20 \mu \mathrm{m}$ wide scratch. The tip potential was set at $-0.7 \mathrm{~V}$ vs $(\mathrm{Ag} / \mathrm{AgCl}, 3 \mathrm{M} \mathrm{KCl})$.

Fig. 9. Nyquist plot of scratched epoxy coated (filled symbols: $\boldsymbol{\Delta}$ after 75 min and $\boldsymbol{\Delta}$ after $1455 \mathrm{~min}$ immersion in the electrolyte) and a scratched microcapsules embodied epoxy coated steel sample (filled symbols: - after $75 \mathrm{~min}$ and $\star 1455 \mathrm{~min}$ immersion in the electrolyte), (solid lines- fit results) 
Fig.10. The change of polarization resistance values in time of scratched epoxy coated ( $\mathbf{\square})$ and a scratched microcapsules embodied epoxy coated steel sample $(\boldsymbol{\Delta})$ immersed in the electrolyte solution. 
Fig. 1.

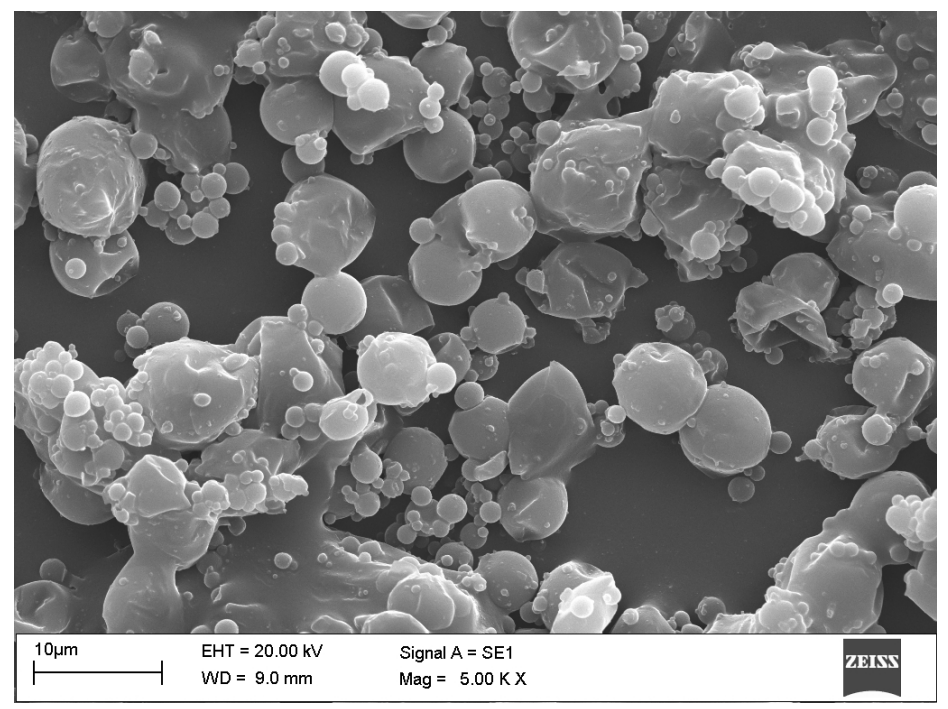

Fig. 2A.

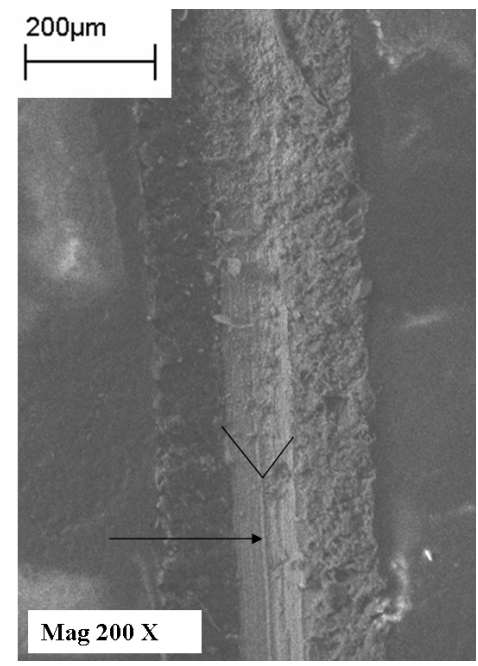

Fig. 2B.

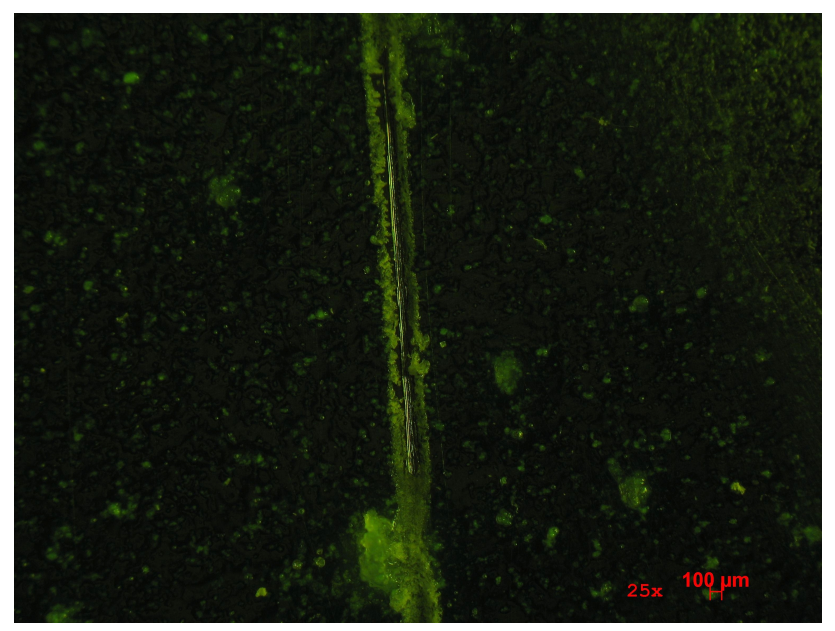


Fig. 2C.

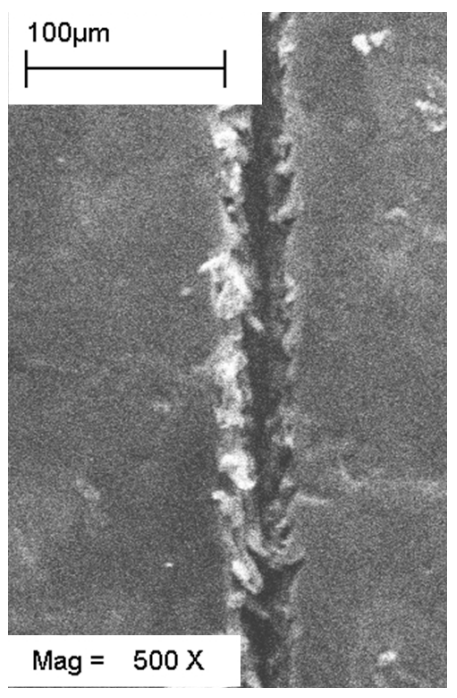

Fig. 2D.

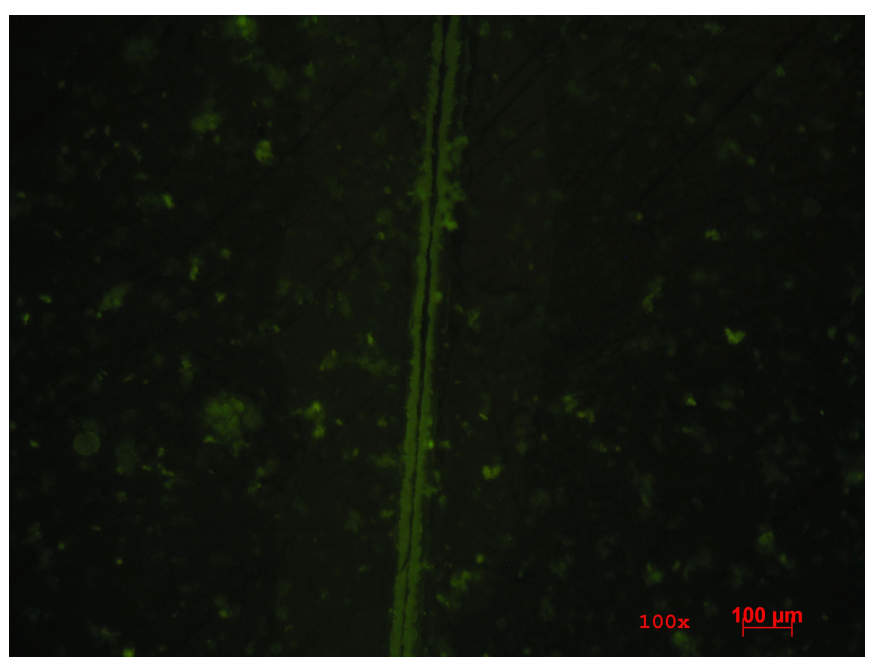

Fig. 3.

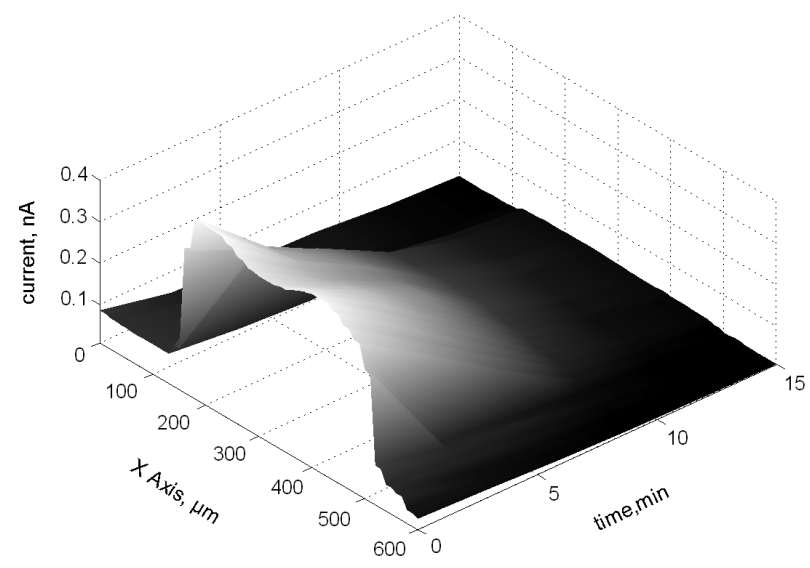

15 
Fig. 4.

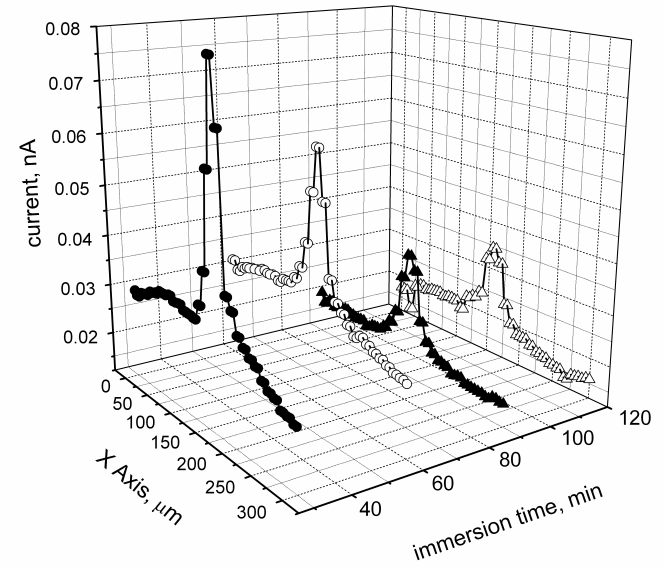

Fig. 5A.

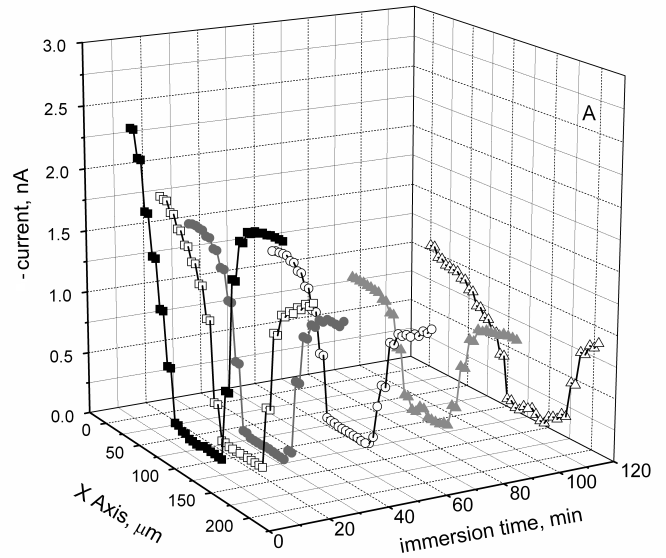

Fig. 5B.

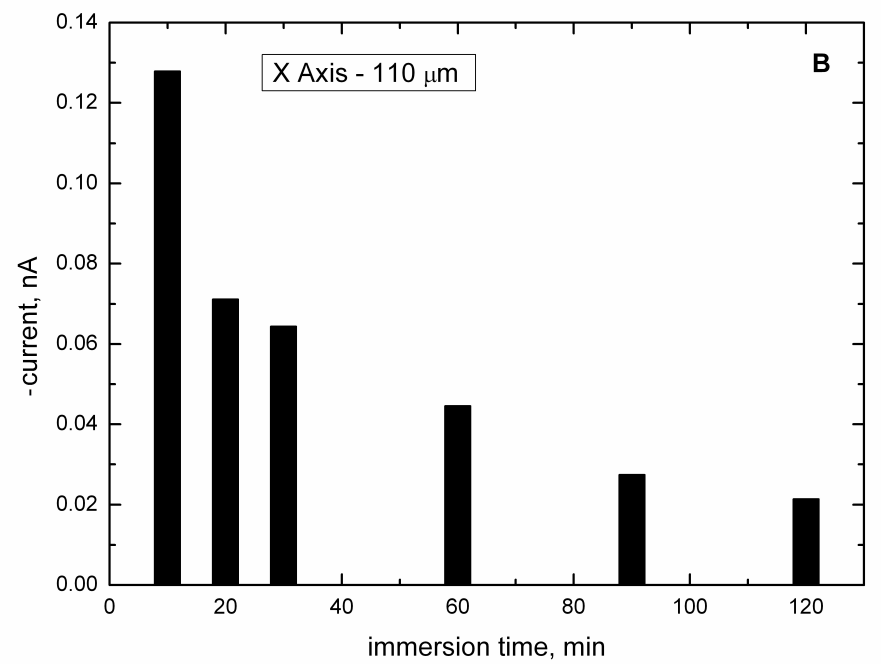


Fig. 6.

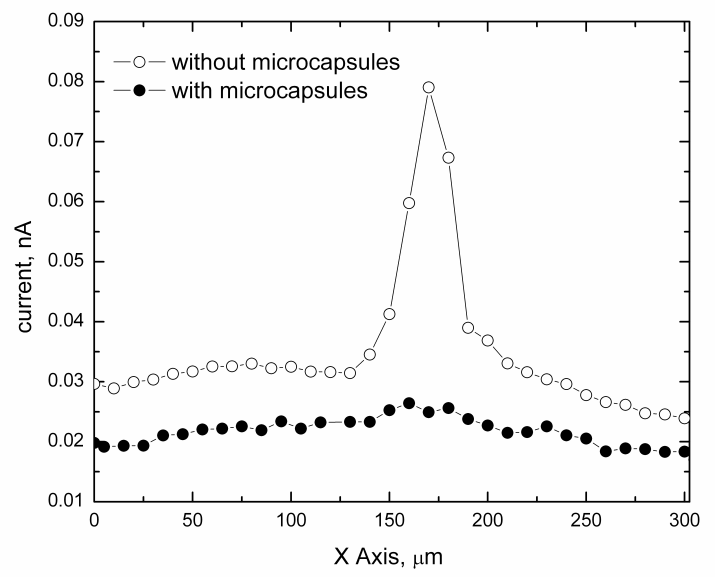

Fig. 7.

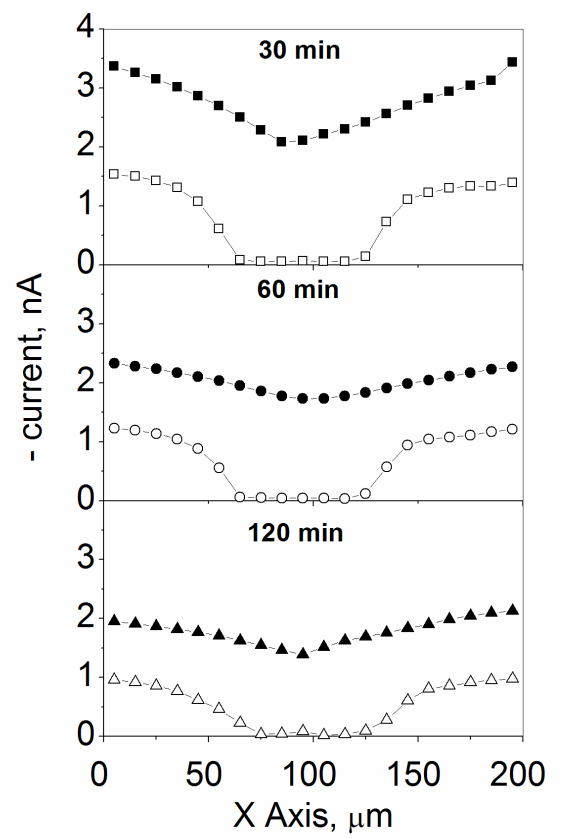


Fig. 8 .

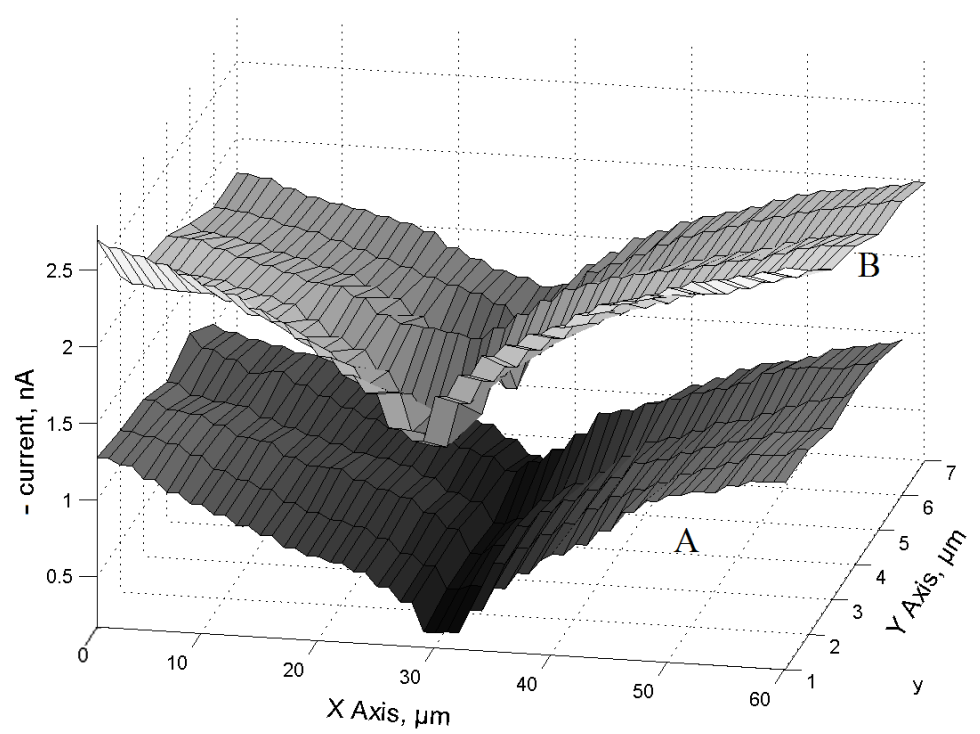

Fig. 9.

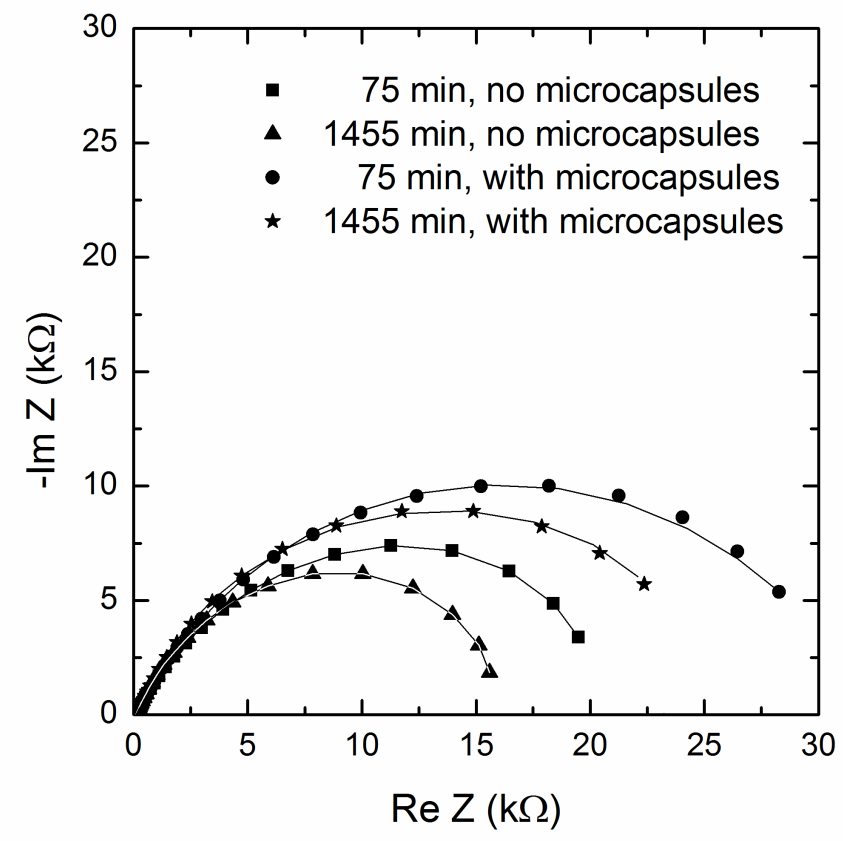


Fig. 10.

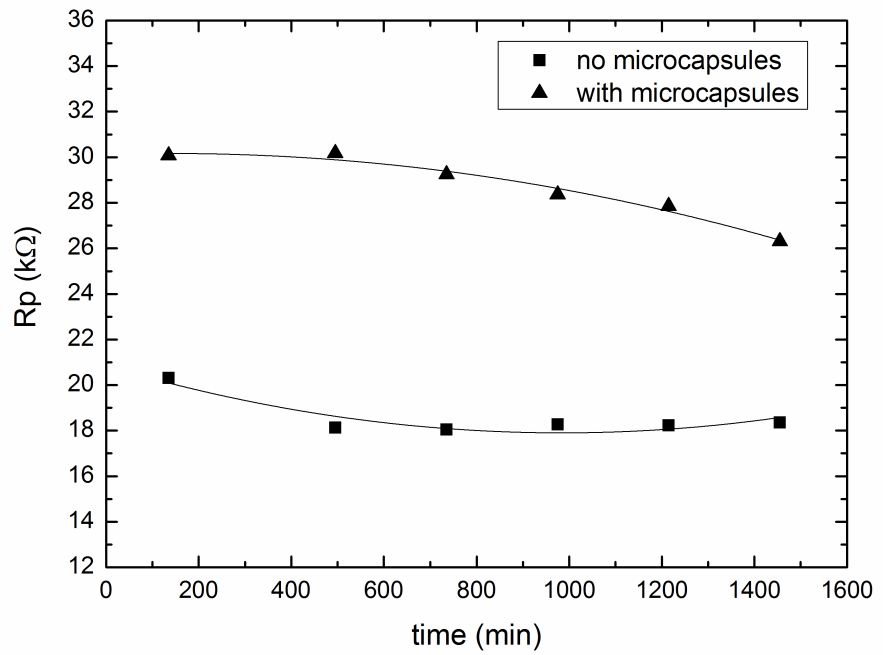

